Review

\title{
Fluorescent Sensing of Fluoride in Cellular System
}

\author{
Yang Jiao', Baocun Zhu², Jihua Chen ${ }^{3}$, Xiaohong Duan ${ }^{1 凶}$ \\ 1. State Key Laboratory of Military Stomatology, Department of Oral Biology, Clinic of Oral Rare Diseases and Genetic Diseases, School of \\ Stomatology, The Fourth Military Medical University, Xi'an, Shaanxi, P. R. China; \\ 2. School of Resources and Environment, University of Jinan, Jinan, Shandong, P. R. China; \\ 3. State Key Laboratory of Military Stomatology, Department of Prosthodontics, School of Stomatology, The Fourth Military Medical \\ University, Xi'an, Shaanxi, P. R. China.
}

\begin{abstract}
$\triangle$ Corresponding author: Xiaohong Duan, Ph. D, Professor, State Key Laboratory of Military Stomatology, Department of Oral Biology, Clinic of Oral Rare Diseases and Genetic Diseases, School of Stomatology, The Fourth Military Medical University, 145 West Changle Road, Xi' an 710032, P.R. China. Tel: 86-29-84776169 FAX: 86-29-84776169 E-mail: xhduan@fmmu.edu.cn.
\end{abstract}

( ) Ivyspring International Publisher. This is an open-access article distributed under the terms of the Creative Commons License (http://creativecommons.org/ licenses/by-nc-nd/3.0/). Reproduction is permitted for personal, noncommercial use, provided that the article is in whole, unmodified, and properly cited.

Received: 2014.06.10; Accepted: 2014.09.22; Published: 2015.01.0I

\begin{abstract}
Fluoride ions have the important roles in a lot of physiological activities related with biological and medical system, such as water fluoridation, caries treatment, and bone disease treatment. Great efforts have been made to develop new methods and strategies for $\mathrm{F}^{-}$detection in the past decades. Traditional methods for the detection of $\mathrm{F}^{-}$including ion chromatography, ion-selective electrodes, and spectroscopic techniques have the limitations in the biomedicine research. The fluorescent probes for $\mathrm{F}^{-}$are very promising that overcome some drawbacks of traditional fluoride detection methods. These probes exhibit high selectivity, high sensitivity as well as quick response to the detection of fluoride anions. The review commences with a brief description of photophysical mechanisms for fluorescent probes for fluoride, including photo induced electron transfer (PET), intramolecular charge transfer (ICT), fluorescence resonance energy transfer (FRET), and excited-state intramolecular proton transfer (ESIPT). Followed by a discussion about common dyes for fluorescent fluoride probes, such as anthracene, naphalimide, pyrene, BODIPY, fluorescein, rhodamine, resorufin, coumarin, cyanine, and near-infrared (NIR) dyes. We divide the fluorescent probes for fluoride in cellular application systems into nine groups, for example, type of hydrogen bonds, type of cleavage of $\mathrm{Si}-\mathrm{O}$ bonds, type of $\mathrm{Si}-\mathrm{O}$ bond cleavage and cylization reactions, etc. We also review the recent reported carriers in the delivery of fluorescent fluoride probes. Seventy-four typical fluorescent fluoride probes are listed and compared in detail, including quantum yield, reaction medium, excitation and emission wavelengths, linear detection range, selectivity for $\mathrm{F}$, mechanism, and analytical applications. Finally, we discuss the future challenges of the application of fluorescent fluoride probes in cellular system and in vivo. We wish that more and more excellent fluorescent fluoride probes will be developed and applied in the biomedicine field in the future.
\end{abstract}

Key words: fluoride; fluorescent probes; fluorophores; cell, in vivo.

\section{Introduction}

Fluoride ion (F-) is widely found in biological systems and the external environment. Proper amount of fluoride may protect teeth from caries and enhance mineral deposition in bone [1]. The American Dental Association (ADA) recommends a fluoride concentration of $0.6 \sim 1.2 \mathrm{mg} / \mathrm{L}$ in bottled water. But high concentration of $\mathrm{F}^{-}$has been demonstrated to be toxic and causing acute or chronic diseases. Over the years, over exposure to fluoride has been related to the occurrence of several types of pathologies in hu- 
mans, such as dental fluorosis, skeleton fluorosis, osteoporosis, metabolic dysfunctions, and cancer [2]. Dental fluorosis appears as unnoticeable, tiny white streaks in the enamel of the tooth in mild forms, and discoloration or brown markings in severe forms, which are permanent or even darken over time. Skeletal fluorosis causes severe pains in joints accompanied with stiffness, which may eventually end with paralysis or the disabled problems. Besides, fluoride can cause neurotoxicity in both laboratory animals and human [3,4]. The double-side effects of fluoride make it very important to monitor the fluoride concentration in vitro and in vivo.

Great efforts have been made to monitor fluoride ions by traditional analytical methods. Ion chromatography, a technique that exploits ion exchange activity to separate ions and polar molecules based on their charge differences, has been used to measure fluoride in mulberry leaves, soil, toothpaste, and other substances. However, chromatographic methods are time consuming and require costly instruments [5]. Another widely used method employs ion-selective electrodes (ISE), which shows a linear relationship for the specific ionic activity within a certain ion concentration range, as electrochemical sensors. The difficulties of ISE include electrode drift, time consumption for equilibration and dissolution of the lanthanum fluoride membrane crystal [6]. Most traditional spectroscopic techniques, which study interactions between matter and radiated energy [7], have similar detection ranges down to the microgram level (Additional file 1: Supplementary Table 1).

The above fluoride detecting methods cannot be employed for biosensing, especially for the in vivo application. In the past decades, fluorescent probes have been broadly studied in biomedicine as promising chemically sensing and analyzing methods that can take the place of traditional analytical methods to some extent. Fluorescent probes make it possible to locate some specific molecules or ions and image them by fluorescence, and transduce the nanoscopic biochemical processes into optical signals. They have become the essential tools in chemistry, medicine, and biochemistry fields [8].

As overdose fluoride may affect multi-tissues in human body, it is important to monitor the trafficking of fluoride in the body, then we will know which tissues or cells easily being targeted by fluoride and avoid the tissue specific toxicity. The advances in fluorescent probes make it possible to simultaneously monitor fluoride ions, in particular, sense and visualize fluoride inside live cells. In this review, we will introduce the general mechanisms for reaction, fluorescent dyes, types and carriers of fluorescent fluoride probes being applied in biosystems. We also analyze the challenges in the future trends of fluorescent fluoride probes in cellular system.

\section{Photophysical Mechanisms for Fluorescent Probes for Fluoride}

Effective fluorescent fluoride probes must meet stringent requirements. They should respond selectively and sensitively to fluoride ions in a complex system that exploits effective fluorescence transduction mechanisms. In general, the mechanisms of fluorescence transduction involves manipulation of electron transfer on binding of the analyte by the probes, including photoinduced electron transfer (PET) [9], intramolecular charge transfer (ICT) [10], fluorescence resonance energy transfer (FRET) [11], excited-state intramolecular proton transfer (ESIPT) [12] and so on.

PET can be pictorially elucidated by molecular orbital theory, during which processes the fluorescence intensity will be decreased, known as "quenching" of the fluorescence [13]. For PET probes, a short aliphatic spacer usually separates the receptor and fluorophore consisting fluorophore-spacerreceptor constructs [14] (Fig. 1). ICT happens from an electron donor to an electron acceptor, conjugated without spacer, and the dipole moment is increased during the process. ICT causes significant shifts in the absorption and emission bands, which reflects the strength of the Donor-Accepter interaction (Fig. 2). The difference between PET and ICT probes is the way of fluorescence response in recognition processes. PET's quenching effect does not cause the specific spectral shifts. In contrast, ICT probes display ratiometric measurements with clear fluorescence band shifts in the binding processes.

FRET is the interaction between donor and acceptor which results in a transfer of excitation energy. The whole process can be influenced by several factors, including the distance between donor and acceptor, the spectrum overlaps between the donor and acceptor, the dipole moment of the molecules and so on $[15,16]$ (Fig. 3). ESIPT commonly happens in the molecules with a five- or a six-membered ring which undergoes tautomerization process accompanied with emission changes. ESIPT chromophores can avoid self-absorption, or the inner filter effect, and improve the fluorescence analysis [17] (Fig. 4). 
A

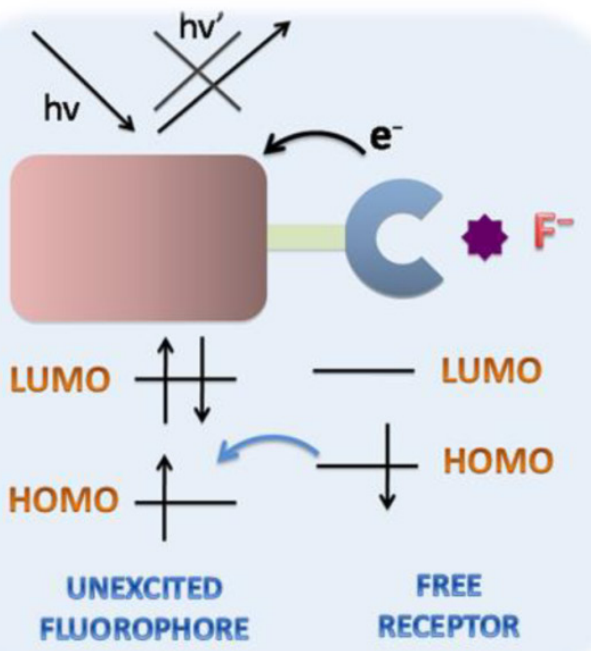

B

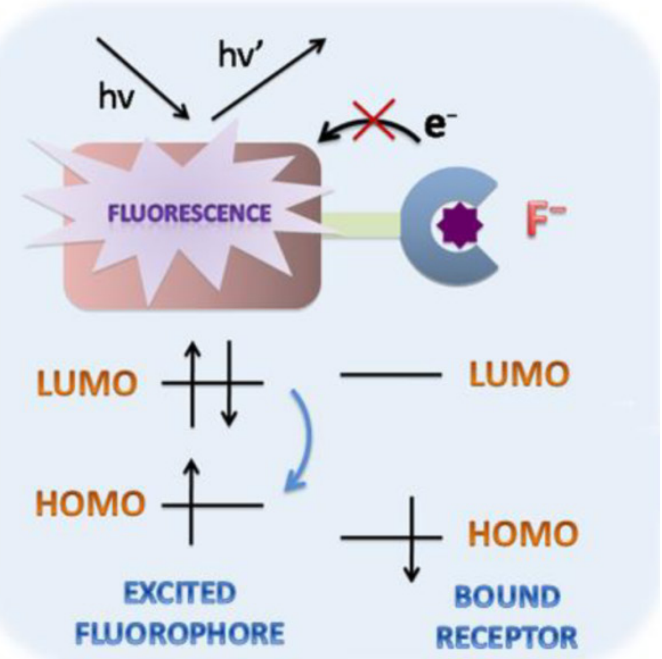

Figure I. Schematic PET mechanisms for fluorescent fluoride probes. A. PET fluorescent fluoride probes is consisted of fluorophore-spacer-receptor constructs, for a short aliphatic spacer separates the fluorophore and receptor. Besides, a relatively high-energy electron pair without bonding is required in the receptors. After excitation, an electron of HOMO is promoted to LUMO, in which a rapid intramolecular electron transfer occurs between the HOMO of receptor and the LUMO of excited fluorophore in the unbound state. The quenching effect of the probe is in the fluorescence "off" state. B. However, the bounded receptor caused electron pair coordinating to F-, making the HOMO of receptor even become lower than that of the fluorophore. The perturbed receptor redox potential slowed down or even switched off the PET process, then causing fluorescence "turned on". HOMO (highest occupied molecular orbital); LUMO (lowest unoccupied molecular orbital).

UNEXCITED FREE FLUOROPHORE RECEPTOR
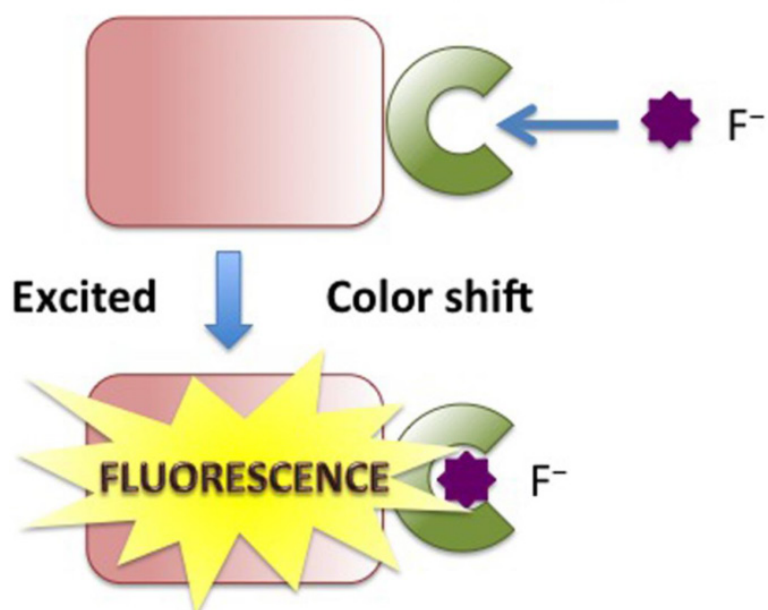

EXCITED

BOUND

\section{FLUOROPHORE RECEPTOR}

Figure 2. Schematic ICT mechanisms in designing fluorescent fluoride probes. The fluorophore possessing an electron-donating group is directly connected to an electron-withdrawing group without spacer. During the recognition processes, the electron density in the fluorophore is affected by the coordination between the recognition group and fluoride, resulting in the color changes of fluorescence emission. ICT causes significant shifts in the absorption and fluorescence emission bands.
A

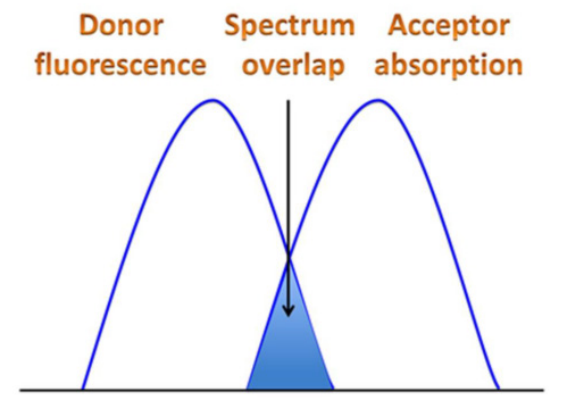

B

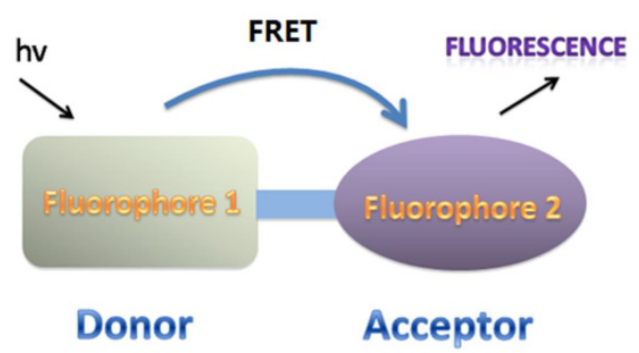

Figure 3. FRET mechanisms for fluorescent fluoride probes. A. Schematic representation of the interaction of two different fluorophores. The extent of spectral overlap between the emission spectrum of fluorophore I (Donor) and the absorption spectrum of fluorophore 2 (Acceptor) is required to allow for FRET to occur. B. FRET happens with an energy transfers from the excited fluorophore I (Donor) to the longer-wavelength fluorophore 2 (Acceptor) $\left(D^{*}+A \rightarrow D+A^{*}\right)$, which is coupled in resonance, causing light emission from the acceptor, accompanied with a loss of emission from the donor. 


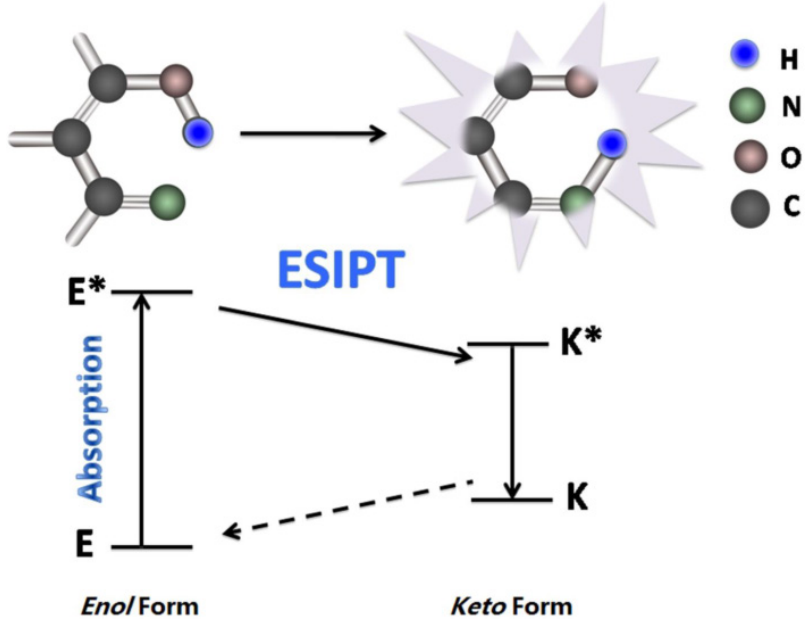

Figure 4. Schematic mechanism of ESIPT for fluorescent fluoride probes. ESIPT is based on the large Stokes' shift. The unexcited molecules usually exist as an enol (E) form in which the intramolecular hydrogen-bond is formed. Upon photo excitation it undergoes an extremely fast tautomerization process into a keto form $\left(E^{*} \rightarrow K^{*}\right)$. Then an ESIPT process occurs and the intramolecular hydrogen-bond stabilizes the keto form. Both radiative decay and the deactivation channel lead to excited keto $\left(\mathrm{K}^{*}\right)$ form to the ground state keto $(\mathrm{K})$ forms. Since the ESIPT is much faster than radiative decay, the fluorescence observed for the ESIPT chromophores is very often. Moreover, the significant differences in absorbing $\left(\mathrm{E}^{*}\right)$ and emitting $\left(\mathrm{K}^{*}\right)$ feature are apt to generate a large Stokes' shifted fluorescence, which is desirable because the self-absorption can be avoided, improving the fluorescence analysis.

\section{Common Dyes for Fluoride Fluorescent Probes}

A suitable fluorophore platform is quite important for fluorescent fluoride probes, and may affect their biological applications and efficiency. The reported dyes for fluorescent fluoride probes include anthracene, naphalimide, pyrene, BODIPY, fluorescein, rhodamine, resorufin, coumarin and cyanine (Fig.5). Near-infrared (NIR) dyes are paid more and more attentions during the recent years. All the molecular formulas of the mentioned fluorescent fluoride probes are listed in supplementary figures (Additional file 1: Supplementary Figure 1, 2, 3, 4).

\section{Anthracene Dyes}

Anthracene consists of three fused benzene rings, and its emission spectrum peaks at $400 \sim 450 \mathrm{~nm}$ under ultraviolet light. Since Kim and Yoon reported a fluorescent PET fluoride probe based on a bisurea-anthracene derivative [18], more PET probes

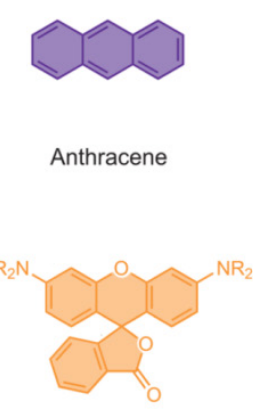

Rhodamine

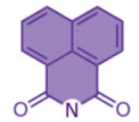

Naphthalimide

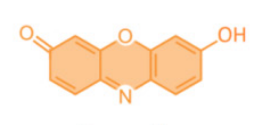

Resorufin

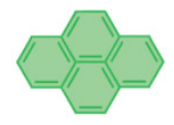

Pyrene

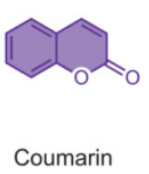

have been designed based on urea-anthracene derivatives and hydrogen-bond theory is mostly used among them. The metal-free organic dyes linked to anthracene-containing $\Pi$-conjugations have also been used for the probe design [19]. Probe 1 was based on anthracene-9,10-dicarbaldehyde bis- $p$-nitrophenylhydrazone and its fluoride detection limit was $2 \times 10^{-6} \mathrm{M}$ [20]. The bond between Probe 1 and F- was recognized as light red to dark brown by naked eye inspection and underwent the intensity changes around $482 \mathrm{~nm}$ and $672 \mathrm{~nm}$, respectively.

\section{Naphthalimide Dyes}

1,8-Naphthalimide probes containing electron donor and acceptor moieties are the typical ICT fluorophores, and are ideal for the construction of colorimetric and ratiometric fluorescence probes. 1,8-Naphthalimide has an excitation wavelength of $420 \mathrm{~nm}$ and is highly desirable for sensing in competitive media. Its derivatives have high stability, quantum yield and convenient functionalization at 4-position site and are broadly applied in fluorescent probes [21]. In an earlier report, Emma et al. demonstrated the use of the 1,8-Naphthalimide in PET probes for anions and the deprotonation could also occur in competition, or in conjunction, with such hydrogen bond [22]. Later, the method was modified either on the aromatic "naphthalene" moiety itself, or at the "N-imide site", which makes it to incorporate with different functional groups and structural motifs possible [23, 24]. Additionally, 1,8-Naphthalimidederived fluorescent fluoride probes can be used to image live cells by two-photon spectroscopy. Zhang et al. synthesized a colorimetric and ratiometric fluorescent Probe 2 that employed 4-amino-1,8naphthalimide as reporter for $\mathrm{F}^{-}$[25]. Upon addition of $120 \mu \mathrm{M} \mathrm{F}$-, Probe 2 showed a $49 \mathrm{~nm}$ red-shift in the emission band from blue to green in $\mathrm{CH}_{3} \mathrm{CN}$, which was based on the fact that $\mathrm{F}^{-}$can promote the cleavage of $\mathrm{Si}-\mathrm{O}$ bond with the release of the green fluorescent 4-amino-1,8-naphthalimide. 


\section{Pyrene Dyes}

Pyrene is consisting of four fused benzene rings in a polycyclic aromatic hydrocarbon structure. Pyrene moiety exhibits intramolecular excimer due to strong п-п interaction between two fluorophore units and excimer emission is changed in the presence of guest ions. Its fluorescence emission spectrum is around 490 520 nm and very sensitive to solvent polarity. The molecules with pyrene have several advantages over other fluorophores, such as the magnitude of the emission intensity ratios between the monomers and the excimers, relatively long lifetimes and the high fluorescence quantum yields [26]. The pyrene excimer transformation mechanism was exploited in fluorescent fluoride Probes 3 and 4. It has two pyrene moieties, which were linked by flexible -O-Si-Si-O- or -O-Si-O- chains [27]. The intracellular pyrene monomer luminescence could be clearly observed within HeLa cells over the short wavelength range $410 \sim 440 \mathrm{~nm}$.

\section{BODIPY Dyes}

Boron-dipyrromethene (BODIPY) dyes have high absorption coefficients, high fluorescence quantum efficiencies, high affinities with silicon, and exceptional stability. Although Treibs and Kreuzer have reported BODIPY-set as early as 1968 [28], it is till the mid 1990s that the application of BODIPY-based dyes in fluorescent probes was fully achieved. Compared to the cyanine dyes and NIR-active fluorophores, the BODIPY dyes have the shorter wavelength emission maxima and smaller extinction coefficients. Liu et al. have realized the direct conversion of BODIPY based fluorescent probes may promote $\left[{ }^{18} \mathrm{~F}\right]$ fluorination of the BODIPY dye emitting in the NIR region in nude mice bearing human U87MG glioblastoma tumors [29]. The application of PET mechanism in BODIPY fluorescent probes has also been reported by other research groups. For example, a BODIPY Probe 5 was synthesized with alkynyl groups as electron donating groups [30]. Because of the high affinity between $\mathrm{Si}$ and $\mathrm{F}^{-}$, the alkynyl groups underwent catalyzed deprotection and electron transfer then occurred in the system. Addition of $\mathrm{F}^{-}$to Probe 5 in $\mathrm{CH}_{2} \mathrm{Cl}_{2}$ resulted in ratiometric changes around $571 \mathrm{~nm} / 551 \mathrm{~nm}$ and $584 \mathrm{~nm} / 564 \mathrm{~nm}$, respectively. BODIPY based Probe 6 contained two dimesitylboryl (Mes $2 \mathrm{~B})$ moieties. It showed intense absorption at $\lambda=576 \mathrm{~nm}$ and a highly efficient orange-red emission at $\lambda=602 \mathrm{~nm}$ in the presence of $\mathrm{F}$ - The reaction processes accompanied with a visually detectable color change from pink to blue [31].

\section{Fluorescein Dyes}

The fluorescein dye with spirolactam structure is non-fluorescent. The ring-opening processes of the spirolactam results in the open form and a strong fluorescence color change [32]. The fluorescence of fluorescein is very intense and its peak excitation and peak emission occurs at $494 \mathrm{~nm}$ and $521 \mathrm{~nm}$, respectively. Due to relatively large visible-range extinction coefficients, high stability against light and high fluorescence quantum yield, it is a widely applied platform in fluorescent sensing for reactive oxygen species and metal cations. Swamy and his colleagues synthesized a fluorescein derivative that bore a boronic acid group as binding site. This probe showed an F-induced emission "off-on" type fluorescence enhancement because the coordination of F- with the ligand groups changed the PET reaction from the amine nitrogen to the photo excited fluorescein moiety [33]. The fluorophore of Probe 7 is a fluorescein moiety which had a better solubility in water. Its tert-butyldimethylsilyl (TBDMS)/tert-butyldiphenylsilyl (TBDPS) group functioned as a fluoride reactive subunit [34]. Upon the addition of F-, Probe 7 penetrated the cellular membrane of HeLa cells and sensitively detected F-. The detection limit was $18 \mu \mathrm{M}$ in HEPES-THF.

\section{Rhodamine dyes}

Rhodamine dyes, belonging to the xanthene class of dyes, generally have high molar absorptivities in the visible region. They show high brightness, good photostability, and the ability to modulate dye's substitution. Rhodamine has different derivatives, and the fluorescence emission spectrum and excitation wavelength of simplest rhodamine are $496 \mathrm{~nm}$ and $517 \mathrm{~nm}$, respectively. Several fluorinated rhodamine derivatives have been synthesized [35]. Sivaraman and Chellappa have reported a rhodamine fluoride probe with high selectivity and colorimetric fluorescence. Fluoride triggered spirolactam ring opening processes caused the fluorescent changes, which was based on the density functional theory calculations and ${ }^{1} \mathrm{HNMR}$ titrations. It could image the intracellular fluoride in HeLa cells [36].

\section{Resorufin Dyes}

Resorufin exhibits maximal emission at $585 \mathrm{~nm}$ and excitation at $550 \mathrm{~nm}$, respectively. It can be exploited as a signaling fluorophore group in cellular system without any damage. The fluorescence emission may be quenched by the alkylation of the 7-hydroxy group in resorufin. The fluoride-induced $\mathrm{Si}-\mathrm{O}$ bond cleavage may cause the release of resorufin, resulting in dual spectroscopic changes. Probe 8 was a dual chromogenic and fluorescent probe. Upon the 
addition of fluoride, it showed an obvious change by UV-Vis observation. It released resorufin through substitution by $\mathrm{F}^{-}$at the silicon center [37]. 3000 equiv of $\mathrm{F}$ - induced 200 -fold enhanced fluorescence intensity at $589 \mathrm{~nm}$ in $\mathrm{CH}_{3} \mathrm{CN} / \mathrm{H}_{2} \mathrm{O}$.

\section{Coumarin Dyes}

Coumarin is one of fragrant organic chemical compounds. It belongs to a classic type of "push-pull" dyes. Upon excitation, an ICT process occurs from the electron donor to the acceptor. Coumarin can be rendered nonfluorescent by caging with trialkylsilyloxy moieties. With the addition of $\mathrm{F}^{-}$, the caging groups are removed and a "turn-on" fluorescence emission was induced which involved the reactive "turn on" fluorescence. Based on DHBC (double hydrophilic block copolymer), Probe 9 was a "turn-on" fluorescent reactive probe for $\mathrm{F}^{-}$with high sensitivity and selectivity [38]. F- induced cyclization produced temperature-sensitive fluorescent coumarin moieties. The unimers and micellar nanoparticles were very sensitive and selective to $\mathrm{F}^{-}$with the detection limits of $0.065 \mathrm{ppm}$ ( diblockunimers ) and $0.05 \mathrm{ppm}$ ( micelles ), respectively. Its drawbacks were that the sensing process was based on the intensity changes of only one single emission band, which made it difficult to calculate concentrations.

\section{Cyanine Dyes}

Cyanine dyes contain two connected nitrogen centers by a polymethine bridge. They have odd number of carbons in the molecule. Cyanine dyes have many merits such as the large extinction coefficients, strong fluorescence, moderate-to-high fluorescence quantum yields and easily tunable maximum of absorption and emission by varying both the length of the polymethine bridge and the heterocyclic structure [39]. Cyanine has different derivatives, and some of them are promising to be NIR region fluorescent probes. Probe $\mathbf{1 0}$ was based on 1-ethyl-4-(p-tert-bytyldimethylsilane ether styryl) quinolinnium iodide, one of cyanine derivatives [40]. Under optimized conditions, absorbance at $600 \mathrm{~nm}$ has a linear relationship with $1.0 \times 10^{-7} \sim 1.0 \times 10^{-4} \mathrm{M}$ fluoride.

\section{NIR dyes}

The absorption and emission bands of the above mentioned dyes are within the ultraviolet-visible (UV-Vis) light range (Fig. 6). It is difficult to use them targeting fluoride in living animals. The limited tissue penetration and auto-fluorescence interference problems usually result in low signal-to-noise ratio. Recent years, researchers have paid more attention to the NIR fluorescent probes which have absorption and emission peaks between 650 900 $\mathrm{nm}$ in vivo bioimaging. These probes have less photo-damage to cells or tissues, deeper tissue penetration, and less cross with auto-fluorescence background [41].

Probe 11 was an earlier NIR "turn-on" fluorescence probe for fluoride with a dicyanomethylene- $4 \mathrm{H}$-chromene moiety. It had several features including high off/on ratio responses as well as high selectivity to fluoride [42]. This probe showed a significant "turn-on" fluorescence response at $718 \mathrm{~nm}$ proportional to fluoride from 0.01 to $2 \mathrm{mM}$ and its detection limit was $8.5 \times 10^{-8}$ M. Probe 12 was based on 1,2,3,3-tetramethyl-3H-indolium iodide and 2-(4-formylphenyl) phenanthroimidazole [43]. The fluoride induced deprotonation of $\mathrm{N}-\mathrm{H}$ on the imidazole moiety attributed to its unique emission in the NIR region and excitation in the visible light region.

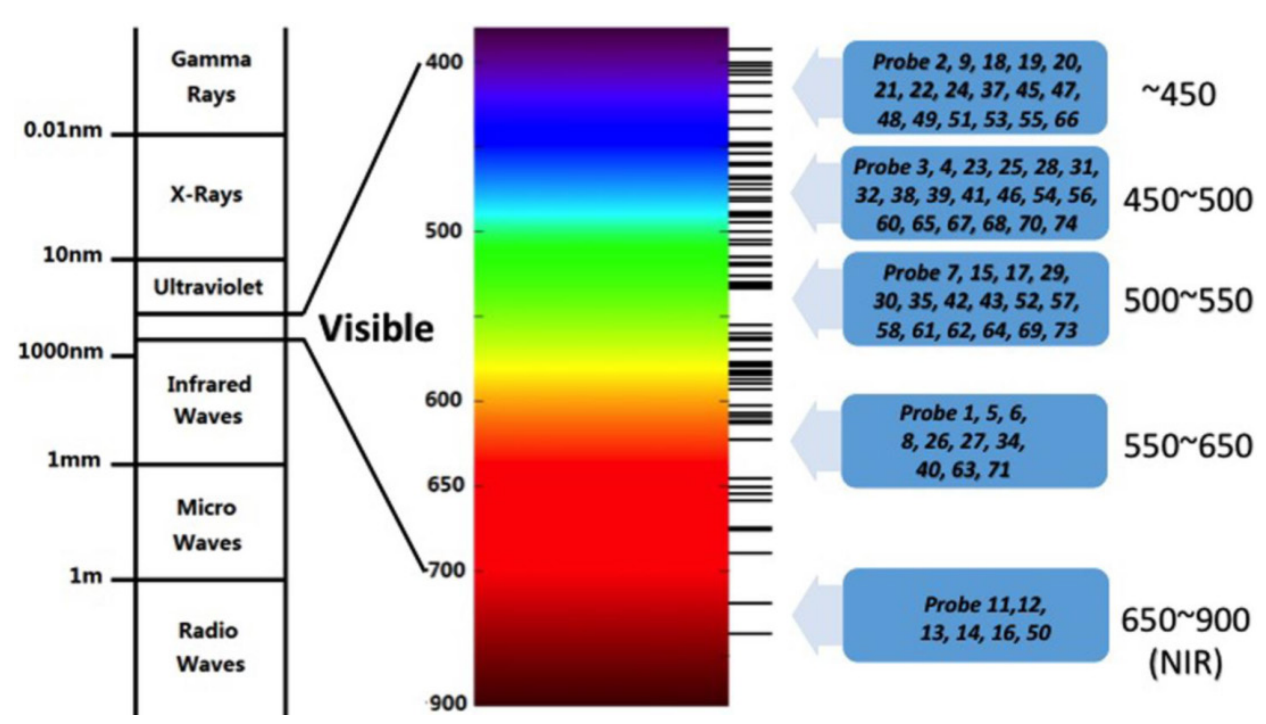

Figure 6. Spectrum distribution of Probe I Probe 74 
Other representing NIR fluoride probes are Probe 13 to Probe 16. The selectivity of Probe 13 towards $\mathrm{F}^{-}$was related with the decreasing HOMO-LUMO gap upon stepwise judicious substitutions over ethylacetoacetate [44]. Probe 14 exploited the extraordinary affinity of $\mathrm{F}^{-}$for $\mathrm{Si}$, and displayed an obvious color change accompanied with a distinct NIR fluorescence upon $\mathrm{F}^{-}$within $30 \mathrm{~s}$ [45]. A fully aromatic D-ח-A-п-D-type molecule 3,6-bis[4-(4(diphenylamino)-phenyl)phenyl]-N-octyl-1,4-diketopyrrolo [3,4-c]pyrrole (TDP) operated as one- and two-photon probe selectively for F- in Probe 15 [46]. But the fluoride induced ratiometric changes in emission spectra upon two-photon were higher than in one-photon excitation. TDP may sense fluoride anions under longer excitation wavelength and lower input laser power.

Some NIR fluoride probes have been used in cell culture system. Probe 16 had a B-Se bond linking a BODIPY dye with benzotrifluoride [47]. After incubated with $1.0 \mu \mathrm{M} \mathrm{F}$ - for $1 \mathrm{~h}$, human hepatoma cells $\left(\mathrm{HepG}_{2}\right)$ showed an increase in the intracellular fluorescence intensity with $1.0 \mu \mathrm{M}$ BODIPY-Se.

\section{Types of Fluorescent Fluoride Probes in biosystems}

\section{Type of Hydrogen-Bond}

The majority of the existing fluorescent fluoride probes are based on the hydrogen bond between $\mathrm{NH}$ group and $\mathrm{F}$. As the smallest and the most electronegative element, fluorine has unique chemical properties and is able to form strong hydrogen-bond with other hydrogen-bearing functional groups, such as NH group (Fig. 7A). The acidic NH groups of hydrogen-bond donor, such as urea, thiourea, and amide, may function as fluoride binding site. Fluoride can in turn deprotonate the acidic amidic $\mathrm{NH}$ groups to block the charge separation and modify the charge dispersion, then a quenching effect is achieved following the PET mechanisms. According to the report, the $\mathrm{pK}_{\mathrm{a}}$ of HF may be 1.5 [48]. Most of hydrogen-bond type fluoride probes were based on PET mechanisms.

On the basis of hydrogen-bond, a series of fluorescent fluoride Probes 17 27 have been designed. Probes 17 and 18 were based on salicylaldehyde-based colorimetric and fluorescent [49], while Probes 19 22 were based on anthraimidazoledione via an ICT process [50]. In order to improve the selectivity and sensitivity, the connecting between polyphenylacetylene and naphthalimide unit in the side chain was used to design the polymer Probes 23 [51]. By the visible detection, Probes 23 could detect $10 \mu \mathrm{M} \sim 100$ $\mu \mathrm{M}$ fluoride. Other hydrogen-bond type fluoride probes include Probes 24 26 in which naphthalimide derivatives were chosen as chromogenic and fluorogenic signaling subunit [52-54].

Despite their high sensitivity and selectivity, hydrogen-bond probes have certain limitations for biosensing because of the high solvability of fluoride in water. The hydration free energy of fluoride is around ca.100 110 kcal / mol, close to the energy in a C-H covalent bond [55]. Most reported hydrogen-bonding fluoride probes work only in organic solvents, and their biological applications are inhibited in water.

Fewer hydrogen-bond type fluoride probes were reported in cell biology study. A phenolic $\mathrm{OH}$ group was employed to design Probe 27 [56] as the color-reporting unit through $\mathrm{F}^{-\cdots} \mathrm{H}-\mathrm{O}$ interactions. It possessed good membrane permeability and accumulated in lysosomes of cells because the fluorescence intensity of Probe 27 could be enhanced in protein containing acidic environments, thus it might be a promising lysosome marking reagent.

A

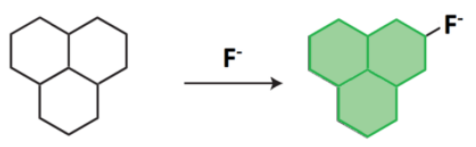

B

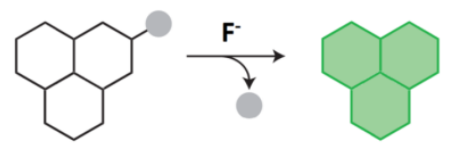

C

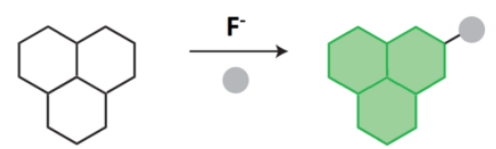

D

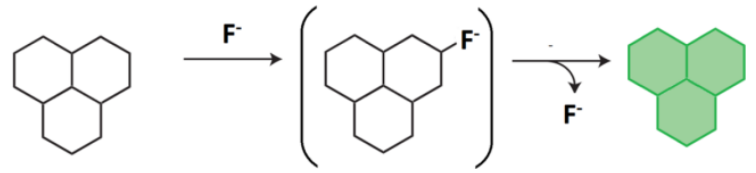

Figure 7. Representative mechanism for fluorescent fluoride probes. A. Binding site-signaling subunit approach (hydrogen-bond and organoboron compounds); B. Bond-cleavage reactions (cleavage of $\mathrm{Si}-\mathrm{O}$ bonds, cleavage of $\mathrm{Si}-\mathrm{O}$ bonds and cylization reactions, and cleavage of $\mathrm{Si}-\mathrm{C}$ bonds); $\mathrm{C}$. Organic addition and metal-ligand substitution approach (nucleophilic addition reaction and metal-mediated fluorescent fluoride probes); D. Tandem reaction cascades to unmask a fluorogenic scaffold (intramolecular hydrogen transfer reaction). The green "polyaromatic" shape is used to represent a generic fluorophore.

\section{Type of Cleavage of Si-O Bonds}

Fluoride may easily remove silyl ether because of the high affinity between fluoride and silicon (Fig. 7B), thus some fluorescent fluoride probes are developed based on fluoride-mediated desilylation such as Probes 28 34. However, the requirements of long reaction time and organic solvent in the reaction systems restrict the utility in biosystem. Recent years, many of them have been modified for the application in cellular research. For example, Lee $e t$ al. designed a 
new coumarin-based Probe 28 which was based on the electron "push-pull" effect and it exhibited a red shift to $500 \mathrm{~nm}$ in emission intensity in aqueous media within $10 \mathrm{~min}$ [57].

TBDMS and TBDPS groups are the most widely used moieties for in vivo fluorescent fluoride probes. TBDPS moiety may be used in place of TBDMS to inhibit the accessibility of water molecules to the silicon atom. Both TBDMS and TBDPS have been used in fluoride-mediated desilylation and sugar-functionalized fluorescent fluoride Probe 29 [58]. Probe 29 was based on the silylation at the phenolic hydroxyl group by TBDMS, and exhibited the properties of fast reactivity, high selectivity, and non-cytotoxicity in aqueous media. The whole reaction required only $5 \mathrm{~min}$ and the detection range was 0.1 to $1 \mathrm{mM}$ in PBS. It showed no toxicity to human carcinoma cell lines at $50 \mathrm{mM}$ and $100 \mathrm{mM}$ by MTT (3-(4,5-dimethyl-2-thiazolyl)-2,5-diphenyl-2-H-tetrazo lium bromide) assay. The sugar residue in Probe 30 improved both water solubility and biocompatibility. In fully aqueous and cellular systems, the probe showed better colorimetric, sensitivity and selectivity toward $\mathrm{F}^{-}$, and presented good imaging of $\mathrm{F}^{-}$in HepG2 cells [59].

TBMCA (TBDMS-7- hydroxycoumarin-4-acetic acid methyl ester) and its bulkier lipophilic TBDPS analog (TBPCA) were designed to reduce cleavage of the silicon group by water in Probe 31 [60]. TBPCA had a high selectivity toward $\mathrm{F}$-against other anions. In A549 human lung epithelial cells, TBPCA fluorescence displayed an intracellular fluoride concentration of $1.86 \times 10^{-2}$ pmol. Probe 32 was consisted of an non-toxic ICT structure and a lipophilic TBDPS moiety [61]. The probe showed a higher selectivity toward $\mathrm{F}^{-}$than other anions with a reaction range from 0.5 to $28 \mathrm{mM}$ and a detection limit of $0.08 \mathrm{mM}$. When it was used to detect RAW 264.7 macrophage cells treated with $3 \mathrm{mM} \mathrm{NaF}$, the significant intracellular fluorescence was observed. Another probe with good cell permeability and intracellular imaging was Probe 33 which contained the relatively hydrophilic TCF (2-dicyanomethylene-3-cyano-4,5,5-trimethyl-2,5-dih ydrofuran) and TBDPS [62]. In addition, Probe 33 could be used to detect F- quantitatively by the ratiometric absorption and "turn-on" fluorescence spectroscopy methods with a detection limit of $0.07 \mathrm{mM}$.

A dual-channel Probe 34 for F- has been developed and synthesized from 4-hydroxy-1,8Naphthalimide and $t$-butyldiphenylsilyl derivative [63]. The probe could quantitatively determine $\mathrm{F}^{-}$both in water and organic media. In $\mathrm{CH}_{3} \mathrm{CN} / \mathrm{H}_{2} \mathrm{O}$, the probe may detect fluoride with a concentration of 0.35 mg/L, lower than EPA's (United States Environmental Protection Agency) requirements, which is 1.0 to
$4.0 \mathrm{mg} / \mathrm{L}$ of fluoride in drinking water. Probe 34 could also be used to detect intracellular fluoride of A549 cells.

\section{Type of Si-O Bond Cleavage and Cylization Reactions}

Probe 35 was synthesized via the cleaved Si-O bond of FTBS (di-tert-butyldimethylsilyl ether). The deprotection of TBS produced a fluorescein spirocycle-opened species in the presence of fluoride [64]. The fluorescence intensity had a linear relationship with fluoride between $0.1 \sim 2.0 \mu \mathrm{M}$ and its limit of detection was $0.041 \mu \mathrm{M}$. Kim and Swager constructed several coumarin derivatives Probe 36 39 with various electrondonating groups as ratiometric probes for F- [65]. Amplification of a "turn-on" conjugated polymer is achieved by FRET mechanisms and the chromophore was linked to the polymer. Comparing with Probe 39, Probe 37 was a small-molecule-based counterpart. Over the same time and with all the same other conditions, Probe 39 was more sensitive, and required a higher $\mathrm{F}^{-}$- concentration for the fluorescence transformation.

\section{Type of Cleavage of Si-C Bonds}

It is well known that the cleavage of $\mathrm{Si}-\mathrm{C}$ is much easier than $\mathrm{Si}-\mathrm{O}$ bond and fluoride ions may trigger the cleavage reaction of the $\mathrm{Si}-\mathrm{C}$ bond in $-\mathrm{C} \equiv \mathrm{C}-\mathrm{SiMe}_{3}$ and generate terminal acetylenes. Such cleavage of Si-C bonds with the addition of fluoride has been used to design fluorescent fluoride probes (Fig. 7B). Fluoride ions could break the $\mathrm{Si}-\mathrm{C}$ bond in $-\mathrm{C} \equiv \mathrm{C}-\mathrm{SiMe}_{3}$ within $5 \mathrm{~min}$ and readily reach equilibrium in a BOIDPY-derivative Probe 40 with a detection limit of $67.4 \mathrm{nM}$ [66]. Probe 41 was developed with core-substituted naphthalene diimide (cNDI)-based receptors for sensing of F- [67]. Upon addition of $\mathrm{F}^{-}$in $\mathrm{CH}_{2} \mathrm{Cl}_{2}$, the cleavage resulted in the remove of the TMS group. The desilylation of the TMS moieties switched on the chromophore emission, and the color was immediately changed from yellow to dark brown.

\section{Type of Organoboron Compounds}

As a Lewis base, $\mathrm{F}^{-}$can strongly interact with boron and cause specific acid base interactions. There is unique LUMO in boron compounds bearing three identical $\Pi$-conjugated groups, and п-conjugation is divergently extended through the vacant $\Pi$-orbital of the boron atom. In the interaction between $\mathrm{F}^{-}$and boron, B-O bonds are broken. The extended $\Pi$-conjugation of the organoboron derivative is interrupted, and an obvious change occurs in their fluorescent properties (Fig. 7A).

There are many reports about fluoride probes based on B-F interactions, such as Probe 42 to Probe 
49. Probe 42 containing a boric acid structure displayed a binding constant of $9.2 \times 10^{10} \mathrm{M}^{-3}$ and exhibited "turn-on" type fluorescence enhancement by the blocking of PET mechanism [33]. When the intramolecular charge transfer happened between electrons from $\mathrm{F}^{-}$and the boron $\Pi$-orbital, Lewis acidic boron-based probes covalently bond with $\mathrm{F}^{-}$, causing the fluorescence quenching. Other defects include poor sensing of $\mathrm{F}^{-}$in aqueous media, cytotoxicity and instability. All these block their biological applications. Many borane-containing asymmetric bidentate probes have been tried to enhance the binding affinity with F- in aqueous solution and increase the ability of capturing F- from water. Probe $\mathbf{4 3}$ was noteworthy due to its heteronuclear bidentate Lewis acid [68]. The 1,8-naphthalenediyl backbone promoted fluoride anion chelation, and enforced the proximity of the two Lewis acidic sites. Thus Probe 43 featured with a high binding constant $\left(2.3 \times 10^{4} \mathrm{M}^{-1}\right)$ in a THF/water $(90 / 10, v / v)$ mixture. Coulombic effects featured to increase anion affinity, and the strong negative inductive effect could be exerted by cationic substituents in Probe 44 [69]. The imidazolium group strongly interacted with $\mathrm{F}^{-}$through a $(\mathrm{C}-\mathrm{H})^{+} \cdots \mathrm{F}-$-type ionic hydrogen-bond. Probe 45 consisting of a boronic acid and an imidazolium moiety, could sense fluoride ranging from 0 to $1.3 \mathrm{mM}$ in $\mathrm{CH}_{3} \mathrm{CN} /$ water $(95 / 5$, v/v, HEPES buffer) solution [70]. Probe 46 with a naphthalimide fluorophore at the axial position also belonged to B-O bond fluoride probes [71].

With polychromophoric systems, many borane-BODIPY dyads Probe $47 \sim 49$ were synthesized. Their two functionalities could be replaced at two positions of phenyl spacer (position 1 and position 3 ) [72]. The two fluorescent chromophores were remarkably close due to the unique " $\mathrm{V}$ " shape structure. The relative direction of the $\mathrm{BMes}_{2}$ and BODIPY units is the major factor to control fluorescent emission. Thus, they could effectively function as sensitive and selective fluorescent probes for fluoride ions. The binding constants were $1.4 \times 10^{5} \mathrm{M}^{-1}, 1.0 \times 10^{5} \mathrm{M}^{-1}$ and $2.2 \times 10^{5} \mathrm{M}^{-1}$, respectively. The selectivity toward $\mathrm{F}^{-}$ was quite remarkable against other interfering species such as $\mathrm{CN}^{-}$[72].

\section{Type of Nucleophilic Addition Reaction}

In the fluoride probes based on the nucleophilic addition reaction, fluoride may react with electron-deficient fluorophores, resulting in the disappearance of the double bond and creation of two new single in the compound (Fig. 7C).

A FRET cassette-type Probe 50 contained two naphthalimide donors and a squaraine acceptor. During its FRET process, the spectral overlap was removed by the decompositions of acceptor chromo- phore [73]. Its detection limit of fluoride was $0.2 \mathrm{mM}$ in acetonitrile by naked eye observation and ratiometric fluorescence analysis. Another example was Probe 51, in which fluoride reacted with maleimide as fluorochrome, which could discriminate $\mathrm{F}$ - from other halogenide anions [74]. The polymerization of maleimide moiety was initiated by the reaction between fluoride and $\mathrm{C}=\mathrm{C}$ double bond. The fluorescence intensity was dramatically increased in 10-fold within 20 minutes and the probe had a detection limit of 50 $\mathrm{mM}$ fluoride.

\section{Type of Intramolecular Hydrogen Transfer Reaction}

The proton transfer process mechanism has contributed to the design of fluorescent fluoride probes for many years (Fig. 7D). The phenolic $\mathrm{OH}$ protons were transferred to $\mathrm{F}^{-}$and produced a spirocycle-opened emissive anionic species, causing the strong fluorescence enhancement at $514 \mathrm{~nm}$ in Probe 52. [75]. Bhalla et al. firstly reported to exploit a cyclization of terphenyl to triphenylene in absence of any oxidizing reagent mechanism to develop fluorescent probe for $\mathrm{F}^{-}$[76]. The addition of $\mathrm{F}^{-}$deprotected OTBS groups of terphenyl derivative in Probe 53 and led to the formation of triphenylene by an irreversible cyclization. The probe showed a detection limit of $2 \times 10^{-6} \mathrm{M}$ fluoride. F- could induce intramolecular cyclization of pyridinium. The charged pyridinium ring and aminophenyl moiety are the two main units of the quenching effect during the PET process in Probe 54 [77]. Probe 54 in $\mathrm{CH}_{3} \mathrm{CN}$ solution exhibited weak fluorescence in the absence of fluoride. The fluoride detection limit of Probe 54 was $2.72 \times 10^{-6} \mathrm{M}$ by fluorescence titration. Based on anion-catalyzed intramolecular hydrogen transfer, pyrazolopyridine was used as a fluorescent as well as chromogenic probe for F- detection in Probe 55 [78].

There are also some biological applications of fluoride probes based on proton transfer processes. Probe 56 was used to detect intracellular fluoride in PC3 prostate tumor-initiating cells and HeLa cells [79]. Probe 56 exhibited the lower cytotoxicity, better water solubility and membrane permeability. Its fluoride detection limit was $8.54 \mathrm{mM}$.

\section{Type of Metal-mediated Fluorescent Probes}

The metal-mediated strategies for fluorescent sensing for $\mathrm{F}$ - have been conducted in many ways. The cleavage reactions are driven by the specific metal ions, varying from hydrolysis, desulfurization to deprotection. The metal induced reaction could release weakly bounded dyes and generate fluorescent signals (Fig. 7C).

Probe 57 was an example of $\mathrm{Al}(\mathrm{III})$ ion mediated 
fluoride probe in which fluoride enabled coordination between two Alizarin Red S molecules and a central $\mathrm{Al}$ (III) ion without interference from other common anions [80]. The binary complex Probe 57 showed sensitive changes to $\mathrm{F}^{-}$ranging from $5 \times 10^{-6}$ to $3 \times 10^{-4}$ M. Im et al. developed a $\mathrm{Cu}^{2+}$ mediated Probe 58 in which TPEN-Cu ${ }^{2+}$ complex was used to mask sulfide ions [81]. Some reports indicated that $-\mathrm{COOH}$ could substitute Zr-EDTA to form ternary complexes, such as $\mathrm{Zr}\left(\mathrm{H}_{2} \mathrm{O}\right)_{2}$ EDTA, causing fluorescent color changes from yellow to blue in Probe 59. Fluoride ions $\left(1.5 \times 10^{-5}\right.$ to $\left.1.5 \times 10^{-4} \mathrm{M}\right)$ may shift the blue to orange red $[82,83]$. A ligand exchange between 3-hydroxy-2'-flavone (FS) bound and Zr-EDTA occurred in Probe 60 consisting of Zr-EDTA and FS [84]. Comparing with - $\mathrm{COOH}$ to coordinate to $\mathrm{Zr}(\mathrm{IV})$, fluoride has a stronger affinity. Fluoride ( 0.10 to $10 \mathrm{mM})$ quenched the strong fluorescence of ( $\mathrm{Zr}$ (CDsCOO $)_{2}$ EDTA) and formed non-fluorescent complex $\mathrm{Zr}(\mathrm{F})_{2} \mathrm{EDTA}$ in Probe 61 [85]. Duan's group has reported continuous research on $\mathrm{Ru}$ mediated fluoride probes $[86,87]$. The photoactive Ru-bipy moiety in Probe 62 enhanced the affinity of fluoride and provided a PET fluorogenic signaling channel [86]. Probe 63 is based on the PET mechanism involving a Ru-bipy fluorophore and a 2,4-dinitrophenylhydrazone [87].

\section{Type of Bifunctional Fluorescent Probes}

As opposed to fluorescent fluoride probes for a single ion, bifunctional probes may independently identify two ions with different spectral responses. The two-stage process is the key by which the probe reacts with the first ion easily visualized by fluorescence changes, and the second ion triggers recognition as a relay host. Bifunctional probes can differentiate and detect analytes with distinct spectroscopic responses by overcoming difficulties such as cross-talk and a large invasive effect.

Probe 64 was designed according to the anion-to-cation relay recognition concept, wherein $\mathrm{F}$ - and $\mathrm{Cu}$ (II) ions were sensed by the two-stage process unprecedentedly via a fluorescence "off-on-off" mechanism [88]. The "turn-on" effect was triggered by the cyclization reaction between fluoride and $\mathrm{Si}$, whilst the quenching "turn-off" effect was caused by $\mathrm{Cu}(\mathrm{II})$. Similarly, Probe 65 used the anion relay recognition concept and proved the highly selective for $\mathrm{F}^{-}$and $\mathrm{CN}^{-}$, based on a unique triple output modes, including fluorescence intensity, color, and absorption band [89]. The fluoride detection limit was 1.86 $\mu \mathrm{M}$ with a significant linear fluorescence response to $\mathrm{F}^{-}(5.0$ to $45.0 \mu \mathrm{M})$. Among another bifunctional fluorescent Probe 66 [90], the 1,3-alternate calix[4]-crown-5 platform selectively bounded potas- sium ions, and the triarylboranes showed enhanced size selectivity toward F-. The alkynyl groups acted as efficient conduits for electron communication, and relayed strong ICT from oxygen to boron [91]. The compound showed the high selectivity and sensitivity for $\mathrm{F}$ - in $\mathrm{CH}_{2} \mathrm{Cl}_{2}$.

The biological biofunctional fluoride probes have also been explored in recent years. The colorimetric and fluorescence response toward $\mathrm{Fe}^{3+}$ and $\mathrm{F}^{-}$ was studied in Probe 67 [92]. Fluoride could reverse the Probe 67-Fe complex formation via the chelation process. MTT assay showed that the HeLa cells' viability was nearly $80 \%$ after being treated with $60 \mathrm{mM}$ Probe 67 for $24 \mathrm{~h}$. The probe had a good cellular permeability and could sense both $\mathrm{Fe}^{3+}$ and $\mathrm{F}$ - inside cells. Probe 68 was developed to sense $\mathrm{F}^{-}$and $\mathrm{Zn}^{2+}$ at the same time in a living organism [93]. Probe 68 was cellular permeable and could be used in fluoride toxicity or bioactivity research in cells.

\section{Carriers of Fluoride Probes}

\section{Polymers}

Polymer-based fluoride probes display several important advantages, such as amplified signal. The binding efficiency and selectivity to fluoride can be increased by carrying polymer chains with various recognition elements [94]. The following polymers have been used in fluorescent fluoride probes, double hydrophilic block copolymer (DHBC), diketopyrrolopyrrole (DPP), etc.

A coil-rod-coil triblock copolymer, P(MMA-co-NBDAE)- $b$-PF- $b$-P(MMA-co-NBDAE) was assembled as micellar nanoparticles in Probe 69 [95]. When the micellar concentration was around $0.1 \mathrm{~g} / \mathrm{L}$ in $\mathrm{C}_{3} \mathrm{H}_{6} \mathrm{O}$ at room temperature $\left(25^{\circ} \mathrm{C}\right)$, Probe 69 could detect $4.78 \mu \mathrm{M} \mathrm{F}^{-}$and was also with a visible color change as well as a colorimetric change. In order to control molecular weight of the polymer and its distribution, reversible addition-fragmentation chain transfer polymerization (RAFT) is generally used [96, 97]. Recently, Tian et al. used RAFT polymerization technique to develop several fluoride polymer probes $[98,99]$. The probe with a higher the molecular weight was more sensitive to $\mathrm{F}^{-}$.

Recently, more researches focus on the way for designing the bioimaging materials with effective sensing capability for fluoride ions and potential high biocompatibility. Hua's group reported a series of fluorescent fluoride probes incorporating Diketopyrrolopyrrole (DPP) core and different electron donor or acceptor moieties [100-102]. By strong deprotonated interaction, fluoride ion might function as a quencher to interrupt electronic energy transfer process, and Probe 71 afforded a fluorescence quenching 
rate of approximately 95\%. It was fabricated into polymeric nanoparticle (diameter of 100 200 nm) for living cell imaging in KB cells. The fluorescent signals were increased gradually with the endocytosis progress. Probe 71 showed a lower cytotoxicity by using a standard MTT assay.

\section{Supramoleculer Gel}

Low-molecular-weight organogelators (LMOGs) can be self-assembled into entangled 3D networks. The weak noncovalent interactions, including $\Pi-\Pi$ interaction, hydrogen-bond, and van der Waals forces in the molecules, usually contribute to the formation of LMOGs [103, 104]. Fluoride might function as one of trigger factors to produce distinct changes in the physical and structural properties $[105,106]$.

The LOMG fluoride probes have the limited ability to detect fluoride ions because they rely on the auxiliary gelating moieties. The sensitivity toward highly polar $\mathrm{F}^{-}$could be lowered by van der Waals interaction. Fluorophores can directly interact with $\mathrm{F}^{-}$ and integrate into LMOGs. The sensitivity toward fluoride could be achieved by responding to the minimized structural modifications in wholly ח-conjugated LMOGs, such as Probe 72. It was one of the wholly $\Pi$-conjugated organic gelators with entangled nanoribbon structures [107]. Fluoride deprotonated the salicylidene aniline moiety, and produced a reversible gel-to-sol transition with the obvious UV-Vis and fluorescence changes.

Probe 73 was based on low-molecular-weight gel consisting of an anthracene chromophore [108]. With the addition of fluoride ions, TBAF promoted gelation of Probe 73 and accompanied a remarkable fluorescence enhancement. Hydrogel Probe 74 contained a water-insoluble silylated fluorescent dye, BTBPA (N-(3-(benzo[d]thiazol-2-yl)-4-(tert-butyldiphenylsilyl oxy)phenyl)acetamide), and selectively traced $\mathrm{F}^{-}$ within 15s at different $\mathrm{pH}$ levels [109]. The hydrogel makes the use of other water-insoluble fluorescent probes possible, which also widens their utility, and avoids adding organic solvents to water-organic solvent composites, thus minimizes negative effects and enhances the accuracy of the results.

All the information about the spectroscopic and analytical parameters of the fluorescent fluoride probes (Probe 1 to Probe 74) is listed in Additional file 1: Supplementary Table 2.

\section{Challenges in the future biosensor of fluoride}

Overdose fluoride may have toxic effects, including influencing cellular signaling pathways, inducing apoptosis and inhibiting function of ion channels $[110,111]$. Besides, fluoride might inhibit the functions of G-protein activator and Ser/Thr phosphatase and affect other important cell signaling [112]. The essential effects of fluoride on the cellular physiological and biological functions urge us to face critical challenges in the applications of fluorescent probes in vivo or in the cellular culture system. An ideal fluorescent probe for biosensing fluoride should possess good aqueous solubility, high sensitivity and selectivity, good chemical and photochemical stability, long excitation and emission wavelengths, low background interference, low or no toxicity, and facile synthetic access [113]. Besides these basic characteristics, here we will only emphasize the following features.

\section{Suitable fluorescent dyes of fluoride probes in living cells or in vivo}

The classical fluorescent probes for fluoride usually have the apparent optical signal changes to realize naked-eye detection [114, 115], or optical response with a huge ratiometric value $(>200 \mathrm{~nm})$ to provide more precise built-in correction with minimized environmental effects [116]. As for the applications in the cellular system, the fluorescent fluoride probes should be exhibiting long wavelength absorption and emission bands, sufficient solubility in water, and good cell membrane permeability [65]. The fluorescent fluoride probes rely much on the instruments which are used to observe the fluoride changes within cells, such as fluorescent microscope, flow cytometer, confocal laser scanning microscope (CLSM), two-photon excitation microscopy analysis. Thus the dyes should match the excitation and emission spectrum of the related detecting instruments. In order to locate the distribution of fluoride, other fluorescent molecules have to be used to label nucleus, endosome, lysosome, or certain proteins. So the dyes in the fluorescent fluoride probes should not react with those fluorescent molecules in a cross-link manner.

With the increasing use of small animal molecular imaging system, more challenges are put forward to fluoride probes and other biomarkers. As we know, small animal models have a great advantage in disease studies that cannot be performed in humans. How to use the molecular imaging technologies as well as imaging instruments to display fluoride in vivo? A recent exciting fluorescent fluoride probe in vivo was reported by Kyo Han Ahn's group. They developed a coumarin derivative for the detection of $\mathrm{F}^{-}$in cells as well as in live zebrafish by one-photon or two-photon microscopy [117]. On the other hand, cellular and tissue imaging in NIR wavelengths between 650 and $900 \mathrm{~nm}$ is advantageous for in vivo imaging [118, 119]. Compared to visible light, NIR dyes are paid more attention due to their lower photo 
damage, fluorescence background, intense photon penetration through deep tissues and light scattering properties. NIR dyes bring light on the effective imaging in deep tissues, which distinguishes NIR-fluoride from other biological chromophores or components, such as water, lipids and hemoglobin. Thus NIR fluorescence imaging for fluoride in cells and small animals might be a future trend. NIR fluoride fluorophores may make it possible to investigate physiological processes within the context of a living organism, and provides the in-time and in-place picture of fluorosis diseases. When NIR fluoride probes are administrated in vivo, one of the essential questions is how to keep the efficient delivery and activation of the probe in the tissue of interest.

\section{Suitable carriers for the delivery of fluoride probes}

Fluoride ion is highly solvated in water and loses its basicity due to hydration. It has a similar hydration free energy with $\mathrm{C}-\mathrm{H}$ covalent bond, which is calculated to be of ca.100 110 kcal/mol. Although some fluoride probes have high sensitivity and selectivity, the delivery of them in vivo or in living cells still remains some problems. For example, hydrogen-bond probes have certain limitations for biosensing fluoride, and some of them work only in organic solvents, and the detection of fluoride ions is inhibited by water [120].

Carriers or scaffolds for the delivery of fluoride probes in vivo are going to be a future trend. Polymers, gel particles or other nanoparticles/materials will draw more attention in the future to design fluoride probes. Polymer based fluoride probes have some advantages comparing to other small organic compounds. They may increase or amplify the fluoride signals by increasing both the binding efficiency and recognition selectivity for specific analytes. Unimers and micellar nanoparticles have been reported to be very sensitive and selective in $\mathrm{F}^{-}$fluorescence measurements. They also show biocompatibility and water dispersibility, as well as the capability of integration with featured temperature-sensing functions. Their drawbacks are that the sensing process is based on the intensity changes of a single emission band, which makes it difficult to calculate concentrations. Some fluoride-responsive LMOGs have excellent sensitivity, for example, after the minimized structural modifications the wholly $\Pi$-conjugated LMOGs can show highly sensitive fluoride responses. In addition, the integration of fluorophores-F- into LMOGs can improve the sensitivity further.
Sensitivity of fluorescent probes for F-in living cells and in vivo

The sensitivity is quite important for detecting intracellular fluoride. Right now the researches on the dynamic function or trafficking of fluoride within cells are delayed due to the limited fluorescent fluoride probes. An ideal fluorescent fluoride probe should be good for monitoring dynamic molecular events, and imaging biological processes of fluoride ions with high precision both in time and in space. However, few fluoride probes match this goal. Unlike other ions (such as $\mathrm{Ca}^{2+}$ ), we know little about the concentration of intracellular fluoride ions, either in cytoplasm or in specific cellular organelles.

Another challenge is the tissue specific blockage which may affect the penetrating of fluoride probes. As we know, tooth and bone tissues are easily targeted by fluoride, whilst these tissues have highly mineralized components, which may block the in vivo sensing of fluoride by the fluorescent probes. Tooth and bone tissues also have high background of auto-fluorescence, which is the major interfering factor for the fluorescent probes. On the other hand, fluoride has different combination forms in the live cells and in tooth/bone tissues. The free status of fluoride ions within cells, or fluorapatite in tooth and bone puts forward the questions for the classical or traditional design ways for the fluoride probes, especially challenging their sensitivity for the future in vivo applications.

\section{Conclusions}

In this review, we have provided an overview of the developments in the area of fluorescent fluoride probes. The traditional measurement methods for $\mathrm{F}^{-}$ are convenient for in vitro samples and are applicable over a wider fluoride detection range. The newly developed fluorescent probes can be exploited for the fluoride detection in living cells or in vivo, applying this reaction-based approach to pre-clinical and clinical diagnostics, or other applications. The fluorescent fluoride probes for the cellular or in vivo applications might be a promising trend in F- detection in the future. We envisage that, in future, the field of fluoride recognition and sensing will continue to expand.

\section{Supplementary Material}

Additional File 1:

Supplementary Figures 1-4. Supplementary Tables

$1-2$.

http://www.thno.org/v05p0173s1.pdf 


\section{Acknowledgments}

We would like to thank Mr. Weimin Huang from Guangdong of P.R.China for his help in drawing the molecular formulas of fluorescent fluoride probes. The authors thank the anonymous reviewers for their comments and critique. This work was supported by National Natural Science Foundation of China $(81470728,81271116$, and 81070819).

\section{Conflicts of interest}

The authors declare no potential conflicts of interest with respect to the authorship and/or publication of this article.

\section{References}

1. Waddington R, Langley M. Altered expression of matrix metalloproteinases within mineralizing bone cells in vitro in the presence of fluoride. Connective tissue research. 2003; 44: 88-95.

2. Gazzano E, Bergandi L, Riganti C, Aldieri E, Doublier S, Costamagna C, et al. Fluoride effects: the two faces of janus. Curr Med Chem. 2010; 17: 2431-41.

3. Grandjean P, Landrigan PJ. Developmental neurotoxicity of industrial chemicals. The Lancet. 2006; 368: 2167-78.

4. Mullenix PJ, Denbesten PK, Schunior A, Kernan WJ. Neurotoxicity of sodium fluoride in rats. Neurotoxicol Teratol. 1995; 17: 169-77.

5. Yuwono M, Ebel S. Determination of fluoride impurities in calcium ascorbate comparison of gas chromatography and ion selective electrode potentiometry. Archiv der Pharmazie. 1997; 330: 348-52.

6. Hawkings R, Corriveau L, Kushneriuk S, Wong P. Dynamic response of the fluoride ion-selective electrode. Analytica Chimica Acta. 1978; 102: 61-83.

7. Krishna MVB, Rao SV, Murthy VSN, Karunasagar D. A simple UV-photolysis digestion method for the determination of fluoride in fluorine-containing drugs by ion-selective electrode and spectrophotometry techniques. Analytical Methods. 2012; 4: 1565-72. doi:Doi 10.1039/C2ay05718b.

8. Yang Y, Zhao Q, Feng W, Li F. Luminescent chemodosimeters for bioimaging. Chem Rev. 2013; 113: 192-270. doi:10.1021/cr2004103.

9. Yuan M, Li Y, Liu H, Li Y. Chemical sensors based on ח-conjugated organic molecules and gold nanoparticles. Science in China Series B: Chemistry. 2009; 52: 715-30.

10. Boens N, Leen V, Dehaen W. Fluorescent indicators based on BODIPY. Chem Soc Rev. 2012; 41: 1130-72. doi:10.1039/c1cs15132k.

11. Kikuchi K. Design, synthesis and biological application of chemical probes for bio-imaging. Chem Soc Rev. 2010; 39: 2048-53. doi:10.1039/b819316a.

12. Zhao J, Ji S, Chen Y, Guo H, Yang P. Excited state intramolecular proton transfer (ESIPT): from principal photophysics to the development of new chromophores and applications in fluorescent molecular probes and luminescent materials. Phys Chem Chem Phys. 2012; 14: 8803-17. doi:10.1039/c2cp23144a.

13. Marcus RA. Electron transfer reactions in chemistry: theory and experiment (Nobel lecture). Angewandte Chemie International Edition in English. 1993; 32: 1111-21.

14. Zhao Y, Zhang XB, Han ZX, Qiao L, Li CY, Jian LX, et al. Highly sensitive and selective colorimetric and off-on fluorescent chemosensor for $\mathrm{Cu}^{2+}$ in aqueous solution and living cells. Anal Chem. 2009; 81: 7022-30. doi:10.1021/ac901127n.

15. Rizzo MA, Springer GH, Granada B, Piston DW. An improved cyan fluorescent protein variant useful for FRET. Nat Biotechnol. 2004; 22: 445-9. doi:10.1038/nbt945.

16. Shih WM, Gryczynski Z, Lakowicz JR, Spudich JA. A FRET-based sensor reveals large ATP hydrolysis-induced conformational changes and three distinct states of the molecular motor myosin. Cell. 2000; 102: 683-94.

17. Iijima T, Momotake A, Shinohara Y, Sato T, Nishimura Y, Arai T. Excited-state intramolecular proton transfer of naphthalene-fused 2-(2' -hydroxyaryl) benzazole family. The Journal of Physical Chemistry A. 2010; 114: 1603-9.

18. Kim SK, Yoon J. A new fluorescent PET chemosensor for fluoride ions. Chem Commun (Camb). 2002;: 770-1.

19. Teng C, Yang XC, Yang C, Li SF, Cheng M, Hagfeldt A, et al. Molecular Design of Anthracene-Bridged Metal-Free Organic Dyes for Efficient Dye-Sensitized Solar Cells. Journal of Physical Chemistry C. 2010; 114: 9101-10. doi:Doi 10.1021/Jp101238k.

20. Huang W, Lin H, Cai Z, Lin H. A novel anthracene-based receptor: highly sensitive fluorescent and colorimetric receptor for fluoride. Talanta. 2010; 81: 967-71. doi:10.1016/j.talanta.2010.01.045

21. de Silva AP, Gunaratne HQ, Gunnlaugsson T, Huxley AJ, McCoy CP, Rademacher JT, et al. Signaling Recognition Events with Fluorescent Sensors and Switches. Chem Rev. 1997; 97: 1515-66.

22. Gunnlaugsson T, Kruger PE, Lee TC, Parkesh R, Pfeffer FM, Hussey GM. Dual responsive chemosensors for anions: the combination of fluorescent PET (photoinduced electron transfer) and colorimetric chemosensors in a single molecule. Tetrahedron Letters. 2003; 44: 6575-8. doi:Doi 10.1016/S0040-4039(03)01699-X.

23. Duke RM, Veale EB, Pfeffer FM, Kruger PE, Gunnlaugsson T. Colorimetric and fluorescent anion sensors: an overview of recent developments in the use of 1,8-naphthalimide-based chemosensors. Chemical Society Reviews. 2010; 39: 3936-53. doi:Doi 10.1039/B910560n

24. Zhu B, Gao C, Zhao Y, Liu C, Li Y, Wei Q, et al. A 4-hydroxynaphthalimide-derived ratiometric fluorescent chemodosimeter for imaging palladium in living cells. Chem Commun (Camb). 2011; 47: 8656-8. doi:10.1039/c1cc13215f.

25. Zhang JF, Lim CS, Bhuniya S, Cho BR, Kim JS. A highly selective colorimetric and ratiometric two-photon fluorescent probe for fluoride ion detection. Org Lett. 2011; 13: 1190-3. doi:10.1021/ol200072e.

26. Winnik FM. Photophysics of preassociated pyrenes in aqueous polymer solutions and in other organized media. Chemical reviews. 1993; 93: 587-614.

27. Gai L, Chen H, Zou B, Lu H, Lai G, Li Z, et al. Ratiometric fluorescence chemodosimeters for fluoride anion based on pyrene excimer/monomer transformation. Chem Commun (Camb). 2012; 48: 10721-3. doi:10.1039/c2cc35967g.

28. Treibs A Kreuzer FH. Difluorboryl-Komplexe von Di-und Tripyrrylmethenen. Justus Liebigs Annalen der Chemie. 1968; 718: 208-23.

29. Liu S, Li D, Zhang Z, Surya Prakash GK, Conti PS, Li Z. Efficient synthesis of fluorescent-PET probes based on [(1)(8)F]BODIPY dye. Chem Commun (Camb). 2014; 50: 7371-3. doi:10.1039/c4cc01411a.

30. Rao MR, Mobin SM, Ravikanth M. Boron-dipyrromethene based specific chemodosimeter for fluoride ion. Tetrahedron. 2010; 66: 1728-34.

31. Sun HB, Dong XC, Liu SJ, Zhao Q, Mou X, Yang HY, et al. Excellent BODIPY Dye Containing Dimesitylboryl Groups as PeT-Based Fluorescent Probes for Fluoride. Journal of Physical Chemistry C. 2011; 115: 19947-54. doi:Doi 10.1021/Jp206396v.

32. Adamczyk M, Grote J. Synthesis of novel spirolactams by reaction of fluorescein methyl ester with amines. Tetrahedron Letters. 2000; 41: 807-9. doi:Doi 10.1016/S0040-4039(99)02197-8.

33. Swamy KM, Lee YJ, Lee HN, Chun J, Kim Y, Kim SJ, et al. A new fluorescein derivative bearing a boronic acid group as a fluorescent chemosensor for fluoride ion. J Org Chem. 2006; 71: 8626-8. doi:10.1021/jo061429x.

34. Cheng X, Jia H, Feng J, Qin J, Li Z. "Reactive" probe for fluoride:"Turn-on" fluorescent sensing in aqueous solution and bioimaging in living cells. Sensors and Actuators B: Chemical. 2014; 199: 54-61.

35. Beija M, Afonso CAM, Martinho JMG. Synthesis and applications of Rhodamine derivatives as fluorescent probes. Chemical Society Reviews. 2009; 38: 2410-33. doi:Doi 10.1039/B901612k.

36. Sivaraman G, Chellappa D. Rhodamine based sensor for naked-eye detection and live cell imaging of fluoride ions. Journal of Materials Chemistry B. 2013; 1: $5768-72$

37. Kim SY, Hong JI. Chromogenic and fluorescent chemodosimeter for detection of fluoride in aqueous solution. Org Lett. 2007; 9: 3109-12. doi:10.1021/ol0711873.

38. Jiang YY, Hu XL, Hu JM, Liu H, Zhong H, Liu SY. Reactive Fluorescence Turn-On Probes for Fluoride Ions in Purely Aqueous Media Fabricated from Functionalized Responsive Block Copolymers. Macromolecules. 2011; 44: 8780-90. doi:Doi 10.1021/Ma2018588.

39. Mishra A, Behera RK, Behera PK, Mishra BK, Behera GB. Cyanines during the 1990s: A Review. Chem Rev. 2000; 100: 1973-2012.

40. Zhu C-Q, Chen J-L, Zheng H, Wu Y-Q, Xu J-G. A colorimetric method for fluoride determination in aqueous samples based on the hydroxyl deprotection reaction of a cyanine dye. Analytica chimica acta. 2005; 539: $311-6$

41. Yuan L, Lin W, Zheng $\mathrm{K}, \mathrm{He} \mathrm{L}$, Huang W. Far-red to near infrared analyte-responsive fluorescent probes based on organic fluorophore platforms for fluorescence imaging. Chem Soc Rev. 2013; 42: 622-61. doi:10.1039/c2cs35313j.

42. Cao J, Zhao C, Zhu W. A near-infrared fluorescence chemodosimeter for fluoride via specific Si-O cleavage. Tetrahedron Letters. 2012; 53: 2107-10.

43. Li T, Yu L, Jin D, Chen B, Li L, Chen L, et al. A colorimetric and fluorescent probe for fluoride anions based on a phenanthroimidazole-cyanine platform. Anal Methods. 2013; 5: 1612-6.

44. Mishra RK, Kumar V, Diwan U, Upadhyay KK, Chowdhury PKR. Designing of a fluoride selective receptor through molecular orbital engineering. Journal of Molecular Structure. 2012; 1027: 167-74. doi:Doi 10.1016/J.Molstruc.2012.06.020

45. Cao J, Zhao C, Feng P, Zhang Y, Zhu W. A colorimetric and ratiometric NIR fluorescent turn-on fluoride chemodosimeter based on BODIPY derivatives: high selectivity via specific Si-O cleavage. RSC Advances. 2012; 2: 418-20.

46. Li YP, Zheng M, Wang JF, Gao YY, Zhang BL, Yang WJ. Two-photon absorption and fluorescence fluoride-sensing properties of N-octyl-3,6-bis[4-(4-(diphenylamino)phenyl)phenyl]-1,4-diketo-pyrrolo[3,4-c] pyrrole. Dyes and Pigments. 2014; 104: 97-101. doi:Doi 10.1016/J.Dyepig.2013.12.031.

47. Gong W, Su RX, Li L, Xu KH, Tang B. A near-infrared fluorescent probe for fluorine ions and its application in the imaging of HepG2 cells. Chinese Science Bulletin. 2011; 56: 3260-5. doi:Doi 10.1007/S11434-011-4662-1.

48. Martinez-Manez R, Sancenon F. Fluorogenic and chromogenic chemosensors and reagents for anions. Chem Rev. 2003; 103: 4419-76. doi:10.1021/cr010421e. 
49. Li Q, Guo Y, Xu J, Shao S. Salicylaldehyde based colorimetric and "turn on" fluorescent sensors for fluoride anion sensing employing hydrogen bonding. Sensors and Actuators B: Chemical. 2011; 158: 427-31.

50. Kumari N, Jha S, Bhattacharya S. Colorimetric probes based on anthraimidazolediones for selective sensing of fluoride and cyanide ion via intramolecular charge transfer. J Org Chem. 2011; 76: 8215-22. doi:10.1021/jo201290a.

51. Qu Y, Hua J, Jiang Y, Tian H. Novel side-chain naphthalimide polyphenylacetylene as a ratiometric fluorescent chemosensor for fluoride ion. Journal of Polymer Science Part A: Polymer Chemistry. 2009; 47: 1544-52.

52. $\mathrm{Li}$ Y, Cao L, Tian H. Fluoride ion-triggered dual fluorescence switch based on naphthalimides winged zinc porphyrin. J Org Chem. 2006; 71: 8279-82. doi:10.1021/jo061161+

53. Liu B, Tian H. A ratiometric fluorescent chemosensor for fluoride ions based on a proton transfer signaling mechanism. Journal of Materials Chemistry. 2005; 15: 2681-6.

54. Liu B, Tian H. A highly selective chromogenic and fluorogenic chemosensor for fluoride ion. Chemistry Letters. 2005; 34: 686-7. doi:Doi $10.1246 / C 1.2005 .686$

55. Esteban-Gomez D, Platas-Iglesias C, de Blas A, Fabbrizzi L, Rodriguez-Blas T. Protonated macrobicyclic hosts containing pyridine head units for anion recognition. Chemistry. 2008; 14: 5829-38. doi:10.1002/chem.200800092.

56. Zheng $X$, Zhu W, Liu D, Ai H, Huang Y, Lu Z. Highly selective colorimetric/fluorometric dual-channel fluoride ion probe, and its capability of differentiating cancer cells. ACS Appl Mater Interfaces. 2014; 6: 7996-8000. doi:10.1021/am501546h

57. Sokkalingam $\mathrm{P}$, Lee $\mathrm{CH}$. Highly sensitive fluorescence "turn-on" indicator for fluoride anion with remarkable selectivity in organic and aqueous media. J Org Chem. 2011; 76: 3820-8. doi:10.1021/jo200138t.

58. Ke B, Chen W, Ni N, Cheng Y, Dai C, Dinh H, et al. A fluorescent probe for rapid aqueous fluoride detection and cell imaging. Chem Commun (Camb). 2013; 49: 2494-6. doi:10.1039/c2cc37270c.

59. Wei G, Yin J, Ma X, Yu S, Wei D, Du Y. A carbohydrate modified fluoride ion sensor and its applications. Anal Chim Acta. 2011; 703: 219-25. doi:10.1016/j.aca.2011.07.009.

60. Kim SY, Park J, Koh M, Park SB, Hong JI. Fluorescent probe for detection of fluoride in water and bioimaging in A549 human lung carcinoma cells. Chem Commun (Camb). 2009:: 4735-7. doi:10.1039/b908745a.

61. Zhu B, Yuan F, Li R, Li Y, Wei Q, Ma Z, et al. A highly selective colorimetric and ratiometric fluorescent chemodosimeter for imaging fluoride ions in living cells. Chem Commun (Camb). 2011; 47: 7098-100. doi:10.1039/c1cc11308a.

62. Zhu B, Kan H, Liu J, Liu H, Wei Q, Du B. A highly selective ratiometric visual and red-emitting fluorescent dual-channel probe for imaging fluoride anions in living cells. Biosens Bioelectron 2014; 52. 298-303. doi:10.1016/j.bios.2013.09.010.

63. Luo ZW, Yang B, Zhong C, Tang F, Yuan M, Xue YB, et al. A dual-channel probe for selective fluoride determination and application in live cell imaging. Dyes and Pigments. 2013; 97: 52-7. doi:Doi 10.1016/J.Dyepig.2012.11.016.

64. Yang XF, Ye SJ, Bai Q, Wang XQ. A fluorescein-based fluorogenic probe for fluoride ion based on the fluoride-induced cleavage of tert-butyldimethylsilyl ether. J Fluoresc. 2007; 17: 81-7. doi:101007/s10895-006-0140-6.

65. Kim TH, Swager TM. A fluorescent self-amplifying wavelength-responsive sensory polymer for fluoride ions. Angew Chem Int Ed Engl. 2003; 42: 4803-6. doi:10.1002/anie.200352075.

66. Fu L, Jiang FL, Fortin D, Harvey PD, Liu Y. A reaction-based chromogenic and fluorescent chemodosimeter for fluoride anions. Chem Commun (Camb). 2011; 47: 5503-5. doi:10.1039/c1cc10784d

67. Buckland D, Bhosale SV, Langford SJ. A chemodosimer based on a core-substituted naphthalene diimide for fluoride ion detection. Tetrahedron Letters. 2011; 52: 1990-2. doi:Doi 10.1016/J.Tetlet.2011.02.080.

68. Melaimi M, Gabbai FP. A heteronuclear bidentate Lewis acid as a phosphorescent fluoride sensor. Journal of the American Chemical Society. 2005; 127: 9680-1. doi:Doi 10.1021/Ja053058s.

69. Kim Y, Gabbai FP. Cationic boranes for the complexation of fluoride ions in water below the 4 ppm maximum contaminant level. J Am Chem Soc. 2009; 131: 3363-9. doi:10.1021/ja8091467.

70. Xu Z, Kim SK, Han SJ, Lee C, Kociok-Kohn G, James TD, et al. Ratiometric Fluorescence Sensing of Fluoride Ions by an Asymmetric Bidentate Receptor Containing a Boronic Acid and Imidazolium Group. European Journal of Organic Chemistry. 2009; 2009: 3058-65. doi:Doi 10.1002/Ejoc.200900120.

71. Li Y, Xu S, Li X, Chen KC, Tian H. An axial subphthalocyanine as ratiometric fluoride ion sensor. Chemistry Letters. 2007; 36: 664-5. doi:Doi 10.1246/Cl.2007.664

72. Swamy PC, Mukherjee S, Thilagar P. Multichannel-emissive V-shaped boryl-BODIPY dyads: synthesis, structure, and remarkably diverse response toward fluoride. Inorg Chem. 2014; 53: 4813-23. doi:10.1021/ic402470a.

73. Yu H, Fu M, Xiao Y. Switching off FRET by analyte-induced decomposition of squaraine energy acceptor: A concept to transform 'turn off'chemodosimeter into ratiometric sensors. Physical Chemistry Chemical Physics. 2010; 12: 7386-91

74. Padié C, Zeitler K. A novel reaction-based, chromogenic and "turn-on" fluorescent chemodosimeter for fluoride detection. New Journal of Chemistry. 2011; 35: 994-7.
75. Zhang $X$, Shiraishi $Y$, Hirai $T$. Unmodified fluorescein as a fluorescent chemosensor for fluoride ion detection. Tetrahedron Letters. 2007; 48: 8803-6. doi:10.1016/j.tetlet.2007.10.086.

76. Bhalla V, Singh H, Kumar M. Facile cyclization of terphenyl to triphenylene: a new chemodosimeter for fluoride ions. Organic letters. 2009; 12: 628-31.

77. Li G, Gong WT, Ye JW, Lin YA, Ning GL. Unprecedented intramolecular cyclization of pyridinium to pyrido[1,2-a]benzimidazole: a novel chemodosimeter for fluoride ions. Tetrahedron Letters. 2011; 52: 1313-6. doi:Doi 10.1016/J.Tetlet.2011.01.057

78. Liu CX, Qian XH, Sun GQ, Zhao LW, Li Z. Chromogenic and fluorescent chemodosimeter for fluoride ion based on novel anion-catalyzed intramolecular hydrogen transfer. New Journal of Chemistry. 2008; 32: 472-6. doi:Doi 10.1039/B712554b.

79. Liu R, Gao Y, Zhang Q, Yang X, Lu X, Ke Z, et al. A fluorescent probe based on hydroxylnaphthalene 2-cyanoacrylate: fluoride ion detection and its bio-imaging in live cells. New Journal of Chemistry. 2014.

80. Sai Sathish R, Ravi Kumar M, Nageswara Rao G, Anil Kumar K, Janardhana C. A water-soluble fluorescent fluoride ion probe based on Alizarin Red S-Al(III) complex. Spectrochim Acta A Mol Biomol Spectrosc. 2007; 66: 457-61. doi:10.1016/j.saa.2006.03.023.

81. Im HG, Kim HY, Choi MG, Chang SK. Reaction-based dual signaling of fluoride ions by resorufin sulfonates. Org Biomol Chem. 2013; 11: 2966-71. doi:10.1039/c3ob00040k

82. Balaji T, Matsunaga $\mathrm{H}$. Naked-eye detection of fluoride using $\mathrm{Zr}$ (IV)-EDTA complex and pyrocatechol violet. Analytical sciences. 2005; 21: 973-7.

83. Wang F, Wu JS, Zhuang XQ, Zhang WJ, Liu WM, Wang PF, et al. A highly selective fluorescent sensor for fluoride in aqueous solution based on the inhibition of excited-state intramolecular proton transfer. Sensors and Actuators B-Chemical. 2010; 146: 260-5. doi:Doi 10.1016/J.Snb.2010.02.007.

84. Matsunaga H, Kanno C, Yamada H, Takahashi Y, Suzuki TM. Fluorometric determination of fluoride ion by reagent tablets containing 3-hydroxy-2'-sulfoflavone and zirconium(IV) ethylenediamine tetraacetate. Talanta. 2006; 68: 1000-4. doi:10.1016/j.talanta.2005.06.068

85. Liu JM, Lin LP, Wang XX, Jiao L, Cui ML, Jiang SL, et al. $\mathrm{Zr}(\mathrm{H} 2 \mathrm{O}) 2 \mathrm{EDTA}$ modulated luminescent carbon dots as fluorescent probes for fluoride detection. Analyst. 2013; 138: 278-83. doi:10.1039/c2an36055a.

86. Zhao Y, Lin Z, Ou S, Duan C, Liao H, Bai Z. A highly selective Ru-based chemosensor for fluoride ion. Inorganic Chemistry Communications. 2006; 9: $802-5$

87. Lin Z-h, Zhao Y-g, Duan C-y, Zhang B-g, Bai Z-p. A highly selective chromo-and fluorogenic dual responding fluoride sensor: naked-eye detection of $\mathrm{F}-$ ion in natural water via a test paper. Dalton Trans. 2006:: 3678-84.

88. Peng Y, Dong YM, Dong M, Wang YW. A selective, sensitive, colorimetric, and fluorescence probe for relay recognition of fluoride and $\mathrm{Cu}(\mathrm{II})$ ions with "off-on-off" switching in ethanol-water solution. J Org Chem. 2012; 77: 9072-80. doi:10.1021/jo301548v

89. Dong M, Peng Y, Dong YM, Tang N, Wang YW. A selective, colorimetric, and fluorescent chemodosimeter for relay recognition of fluoride and cyanide anions based on 1,1'-binaphthyl scaffold. Org Lett. 2012; 14: 130-3. doi:10.1021/ol202926e

90. He X, Yam VW. A highly selective bifunctional luminescence probe for potassium and fluoride ions. Org Lett. 2011; 13: 2172-5. doi:10.1021/ol200277n.

91. Kim JS, Quang DT. Calixarene-derived fluorescent probes. Chem Rev. 2007; 107: 3780-99. doi:10.1021/cr068046j.

92. Kar C, Samanta S, Mukherjee S, Datta BK, Ramesh A, Das G. A simple and efficient fluorophoric probe for dual sensing of Fe 3+ and F-: application to bioimaging in native cellular iron pools and live cells. New Journal of Chemistry. 2014; 38: 2660-9.

93. Li YP, Zhao $\mathrm{O}$, Yang HR, Liu SJ, Liu XM, Zhang $\mathrm{YH}$, et al. A new ditopic ratiometric receptor for detecting zinc and fluoride ions in living cells. Analyst. 2013; 138: 5486-94. doi:10.1039/c3an00351e.

94. Kim HN, Guo Z, Zhu W, Yoon J, Tian H. Recent progress on polymer-based fluorescent and colorimetric chemosensors. Chem Soc Rev. 2011; 40: 79-93. doi:10.1039/c0cs00058b.

95. Hu J, Zhang G, Geng Y, Liu S. Micellar Nanoparticles of Coil-Rod-Coil Triblock Copolymers for Highly Sensitive and Ratiometric Fluorescent Detection of Fluoride Ions. Macromolecules. 2011; 44: 8207-14. doi:10.1021/ma201777p.

96. Moad G, Rizzardo E, Thang SH. Radical addition-fragmentation chemistry in polymer synthesis. Polymer. 2008; 49: 1079-131.

97. Nghiem QD, Nguyen CT, Kim DP. Controlled/living radical polymerization of vinylcyclicsilazane by RAFT process and their block copolymers. Journal of Polymer Science Part a-Polymer Chemistry. 2008; 46: 4594-601. doi:Doi 10.1002/Pola.22804

98. Jiang J, Xiao X, Zhao P, Tian H. Colorimetric naked-eye recognizable anion sensors synthesized via RAFT polymerization. Journal of Polymer Science Part A: Polymer Chemistry. 2010; 48: 1551-6.

99. Zhao P, Jiang J, Leng B, Tian H. Polymer Fluoride Sensors Synthesized by RAFT Polymerization. Macromol Rapid Commun. 2009; 30: 1715-8. doi:10.1002/marc.200900318

100. Qu Y, Hua J, Tian H. Colorimetric and ratiometric red fluorescent chemosensor for fluoride ion based on diketopyrrolopyrrole. Org Lett. 2010; 12: 3320-3. doi:10.1021/ol101081m.

101. Qu Y, Qu S, Yang L, Hua J, Qu D. A red-emission diketopyrrolopyrrole-based fluoride ion chemosensor with high contrast ratio working in a dual mode: 
solvent-dependent ratiometric and "turn on" pathways. Sensors and Actuators B: Chemical. 2012; 173: 225-33.

102. Qu Y, Wu YQ, Gao YT, Qu SY, Yang L, Hua JL. Diketopyrrolopyrrole-based fluorescent conjugated polymer for application of sensing fluoride ion and bioimaging. Sensors and Actuators B-Chemical. 2014; 197: 13-9. doi:Doi 10.1016/J.Snb.2014.02.065.

103. Piepenbrock M-OM, Lloyd GO, Clarke N, Steed JW. Metal-and anion-binding supramolecular gels. Chemical reviews. 2009; 110: 1960-2004.

104. Sangeetha NM, Maitra U. Supramolecular gels: functions and uses. Chem Soc Rev. 2005; 34: 821-36. doi:10.1039/b417081b.

105. Maeda H. Anion-responsive supramolecular gels. Chemistry. 2008; 14: 11274-82. doi:10.1002/chem.200801333.

106. Cametti M, Rissanen K. Highlights on contemporary recognition and sensing of fluoride anion in solution and in the solid state. Chem Soc Rev. 2013; 42: 2016-38. doi:10.1039/c2cs35439j.

107. Lee J, Kwon JE, You Y, Park SY. Wholly п-Conjugated Low-Molecular-Weight Organogelator That Displays Triple-Channel Responses to Fluoride Ions. Langmuir. 2014; 30: 2842-51.

108. Rajamalli P, Prasad E. Low molecular weight fluorescent organogel for fluoride ion detection. Org Lett. 2011; 13: 3714-7. doi:10.1021/ol201325j.

109. Xiong L, Feng J, Hu R, Wang S, Li S, Li Y, et al. Sensing in $15 \mathrm{~s}$ for aqueous fluoride anion by water-insoluble fluorescent probe incorporating hydrogel. Anal Chem. 2013; 85: 4113-9. doi:10.1021/ac400252u.

110. Arhima MH, Gulati OP, Sharma SC. The effect of Pycnogenol on fluoride induced rat kidney lysosomal damage in vitro. Phytother Res. 2004; 18: 244-6. doi:10.1002/ptr.1395.

111. Duan X, Mao Y, Wen X, Yang T, Xue Y. Excess fluoride interferes with chloride-channel-dependent endocytosis in ameloblasts. J Dent Res. 2011; 90: 175-80. doi:10.1177/0022034510385687.

112. Cheng TJ, Chen TM, Chen CH, Lai YK. Induction of stress response and differential expression of $70 \mathrm{kDa}$ stress proteins by sodium fluoride in $\mathrm{HeLa}$ and rat brain tumor 9L cells. J Cell Biochem. 1998; 69: 221-31.

113. Morandi S, Morandi F, Caselli E, Shoichet BK, Prati F. Structure-based optimization of cephalothin-analogue boronic acids as $\beta$-lactamase inhibitors. Bioorganic \& medicinal chemistry. 2008; 16: 1195-205.

114. Hu R, Feng J, Hu D, Wang S, Li S, Li Y, et al. A rapid aqueous fluoride ion sensor with dual output modes. Angew Chem Int Ed Engl. 2010; 49: 4915-8. doi:10.1002/anie.201000790.

115. Cheng X, Li S, Xu G, Li C, Qin J, Li Z. A Reaction-Based Colorimetric Fluoride Probe: Rapid "Naked-Eye" Detection and Large Absorption Shift. ChemPlusChem. 2012; 77: 908-13.

116. Han F, Bao Y, Yang Z, Fyles TM, Zhao J, Peng X, et al. Simple Bisthiocarbonohydrazones as Sensitive, Selective, Colorimetric, and Switch-On Fluorescent Chemosensors for Fluoride Anions. Chemistry-A European Journal. 2007; 13: 2880-92.

117. Kim D, Singha S, Wang T, Seo E, Lee JH, Lee SJ, et al. In vivo two-photon fluorescent imaging of fluoride with a desilylation-based reactive probe. Chem Commun (Camb). 2012; 48: 10243-5. doi:10.1039/c2cc35668f.

118. Zhang X, Bloch S, Akers W, Achilefu S. Near-infrared molecular probes for in vivo imaging. Curr Protoc Cytom. 2012; Chapter 12: Unit12 27. doi:10.1002/0471142956.cy1227s60.

119. Youn H, Hong KJ. In vivo Noninvasive Small Animal Molecular Imaging. Osong Public Health Res Perspect. 2012; 3: 48-59. doi:10.1016/j.phrp.2012.02.002.

120. Black CB, Andrioletti B, Try AC, Ruiperez C, Sessler JL. Dipyrrolylquinoxalines: Efficient sensors for fluoride anion in organic solution. Journal of the American Chemical Society. 1999; 121: 10438-9. doi:Doi 10.1021/Ja992579a. 